\title{
Analisis Pengaruh Bauran Pemasaran Terhadap keputusan Pembelian
}

\section{Richard Berlien}

Sekolah Tinggi Akuntansi dan Manajemen Indonesia richardberlien@gmail.com

\section{Sumaizar}

Sekolah Tinggi Akuntansi dan Manajemen Indonesia sumaizar@gmail.com

\section{Satria Sinambela}

Sekolah Tinggi Akuntansi dan Manajemen Indonesia satriaanna11@gmail.com
Abstract
Tea Powder is a delicious beverage powder in Sidamanik. In developing the business, the company will expand the sales area in each sub district. The company chooses the low end segment, which is considered to be at low cost, and determines product positioning only in the sweet bread market. Management has conducted the marketing mix strategy. But, the effectiveness is still being argued, especially regarding the problems of the expansion of sales area. Thus, the scientifically conducted study is needed to measure the marketing mix and its influence on the decision, statisfaction, and the loyalty of customers. Results of the study showed that the overall hypothesis were acceptable and there were significant influences of the product, distribution, and promotion on consumers' decison; there were significant influences of product and price on consumers' satisfaction; there were significant influences of consumers' decision on consumers' satisfaction and loyalty, and there was a significant influence of consumers' satisfaction on consumers' loyalty.

Keywords Product, Price, Distribution, Promotion, Decision, Satisfaction, Loyalty

\section{PENDAHULUAN}

Strategi sesuai tag line tersebut dimaksudkan untuk daya dukung merek yang berkelanjutan dengan tingkat: brand awareness, brand acquisition, brand equity dan akhirnya brand loyalty. Perusahaan memilih segmen low end yang diwujudkan dengan harga murah, dan menentukan product positioning pada pasar roti manis (bukan roti tawar, kue tart, kue basah/jajan pasar) yang diidentikkan manis sama dengan enak. Pada segmen low end dan product positioning tersebut, terjadi tingkat persaingan yang sangat ketat berupa feature, advantage, benefit namun tidak pada value, sehingga fresh from the oven adalah value yang dipilih perusahaan sebagai pembeda dengan kompetitor yang dimaksudkan agar para pelanggannya mendapatkan roti yang disajikan baru keluar dari oven. Dengan rasa yang berbeda tersebut perusahaan bermaksud menjadikan pelanggan menjadi setia pada merek.

Strategi yang dipilih perusahaan adalah strategic competitiveness yang dicapai apabila sebuah perusahaan dengan baik merumuskan serta menerapkan strategi penciptaan nilai yang artinya perusahaan memiliki keunggulan bersaing yang berkesinambungan atau sustained or sustainable competitive advantage (Kotler dan Keller, 2009:320). Suatu perusahaan diyakini memiliki keunggulan bersaing yang berkesinambungan hanya setelah usaha pesaingnya meniru 
strategi mereka namun berakhir dengan kegagalan. Walaupun suatu perusahaan dapat mencapai keunggulan bersaing, biasanya hanya dapat mempertahankan keunggulan itu untuk sementara saja. Keunggulan bersaing yang berkesinambungan menghasilkan laba diatas rata-rata (above average profits). Dari strategi strategic competitiveness perusahaan melakukan langkah taktik melalui system block coverage area dengan metode personal selling dan teknik intensive calls sebagai langkah operasionalnya.

Manajemen bermaksud akan melakukan perluasan area penjualan ke seluruh kecamatan di Indonesia secara bertahap dengan metode personal selling dengan kunjungan pada pembeli atau pelanggan yang intensif (intensive calls) sebagai tekniknya. Hal yang perlu dipertimbangkan oleh manajemen adalah kelayakan (feasibility) model penjualan yang dipergunakan, maka akan muncul sebuah masalah kelayakan dari metode personal selling dan intensive calls, yaitu kemampuan mencapai volume penjualan tertentu, kemampuan mendapatkan laba tertentu, dan kemampuan menunjang pertumbuhan perusahaan. Pengertian layak dalam penelitian ini adalah kemungkinan dari gagasan usaha/proyek yang akan dilaksanakan memberikan manfaat (benefit), baik dalam arti financial benefit maupun dalam arti social benefit.

Aspek yang menjadi pertimbangan dalam kelayakan bisnis, yaitu: aspek pasar dan pemasaran, aspek teknis dan teknologi, serta aspek ekonomi dan keuangan. Social benefit yang akan menjadi perhatian dalam penelitian ini adalah komunitas dengan output terciptanya wirausaha baru yang bergerak di bidang waralaba. Memang Bubuk Teh baru didirikan, namun selalu optimis untuk terus tumbuh dan berkembang. Malcolm (1992:1) menyatakan bahwa diperlukan langkah efektif untuk tahap perkenalan perusahaan yang saling berhubungan, yaitu: audit, tujuan, strategi, dan rencana untuk melaksanakannya, untuk menempatkan perusahaan dimasa mendatang agar dapat tercapai pertumbuhan, kedewasaan dan kemampuan mengatasi kemunduran. Model yang dipakai dalam metode personal selling dengan teknik intensive calls berbasis pada sumber daya untuk profitabilitas tinggi. Model tersebut diaplikasikan oleh peneliti untuk mempermudah rangkaian pembahasan dalam penelitian ini:

1. Sumber daya adalah input bagi proses produksi perusahaan yang berupa: modal fisik, sumber daya manusia, dan organisasi.

2. Kemampuan (capability) adalah kapasitas sekumpulan sumber daya untuk melakukan tugas atau aktivitas secara integratif.

3. Keunggulan bersaing yang berkesinambungan terjadi pada saat perusahaan menerapkan suatu strategi penciptaan nilai dan perusahaan pesaing tidak mampu menerapkannyasecara berkesinambungan, serta saat perusahaan lain tidak mampu meniru keunggulan strategi tersebut, atau kemampuan perusahaan untuk mengungguli pesaingnya dalam hal profitabilitas.

4. Penerapan strategi adalah tindakan yang diambil untuk memperoleh laba tinggi.

5. Profitabilitas tinggi adalah pencapaian laba diatas rata-rata.

Tujuan dari intensive calls atau kunjungan rutin untuk pembelian ulang adalah: (1) reaching the prospect dengan mengunjungi calon pembeli, (2) making the sale, yaitu menciptakan pembelian atau terciptanya pembeli, dan (3) developing the relationship dengan menjadikan pembeli sebagai pelanggan.

Struktur sistem pelaporan dari perusahaan adalah sebagai berikut:

1. Estimasi atau perkiraan yang direncanakan dalam bentuk:

a. Target callsatau target atas jumlah pelanggan yang harus dikunjungi, b. Target pack atau target penjualan yang diukur per bungkus,

b. Target rupiah atau target penjualan yang diukur dengan nilai rupiah.

2. Realisasi atau pencapaian penjualan dalam pelaksanaan di lapangan:

a. Actual calls atau kenyataan kunjungan atas pelanggan;

b. Effective callsatau terjadinya transaksi (closed) oleh pembeli yang dikunjungi, 
c. Effective pack atau terjadinya transaksi (closed) oleh pembeli yang dikunjungi yang diukur per bungkus,

d. Target rupiah, atau terjadinya transaksi (closed) oleh pembeli yang dikunjungi yang diukur dengan nilai rupiah.

3. Proyeksi untuk memperkirakan penjualan tahun akan datang disebut prosperity card.

Untuk menjalankan aktivitas operasional penjualan, perusahaan memperkerjakan salesman. Aktivitas administrasi yang dikerjakan harian sebagai data kuantitatif adalah: (a) daily calls sheet, yang disebut juga laporan kunjungan atas pembelian harian, (b) daily issue, disebut juga laporan perhitungan persediaan dan keuangan harian, (c) customer record card atau data pelanggan yang dikunjungi secara berkala.

Jumlah tenaga salesman yang melaksanakan penjualan saat ini terdiri atas 6 orang.Metode yang dilakukan dalam penjualan adalah personal selling, dengan menerapkan proses persuasi yang menurut Mowen dan Minor (2002:356) merupakan usaha eksplisit untuk mempengaruhi kepercayaan, sikap dan/atau perilaku dengan teknik sebagai berikut:

1. Teknik di muka pintu (foot-in-the-door technique) dilakukan melalui mekanisme persepsi diri. Dengan mengikuti permintaan pertama yang lebih kecil, calon konsumen membentuk kesan bahwa ia adalah jenis orang yang melakukan hal tersebut. Selanjutnya, ketika permintaan kedua dibuat, calon konsumen biasanya setuju dengan permintaan tersebut yang secara sederhana berasal dari kebutuhan yang konsisten dengan persepsi diri.

2. Teknik berhadapan langsung (door-in-the-face technique) dalam teknik ini muncul norm of reciprocity (norma timbal balik) yang menyatakan bahwa jika seseorang melakukan sesuatu untuk Anda, maka Anda juga harus melakukan sesuatu sebagai imbalannya. Norma ini memperbaiki keadaan masyarakat dengan mayakinkan bahwa usaha kita membantu orang lain pasti ada balasannya.

3. Teknik walau hanya satu-sen-akan-membantu (even-a-penny-will-help technique) didasarkan atas tendensi universal bagi orang yang ingin membuat dirinya "kelihatan baik".

4. Teknik mengambil hati (ingratiation) mangacu pada taktik pelayanan sendiri (self serving) yang dilakukan oleh salesman agar dirinya kelihatan menarik bagi orang lain.

Dari segi jumlah salesman, untuk saat ini dianggap memadai untuk target calls sebanyak 60 kunjungan per hari yang mana dalam melaksanakan tugas dan kegiatan mereka berpedoman pada analisis jabatan dan evaluasi secara kualitatif. Namun hingga saat ini belum pernah dilaksanakan pengukuran atas efektivitas bauran pemasaran sebagai proses dalam menciptakan permintaan sehingga terjadi peningkatan penjualan yang berkelanjutankarena bagaimanapun, terjadinya pembelian (closing) adalah hasil (outcome) bagi perusahaan. Oleh karena itu, faktorfaktor apa yang mempengaruhi keputusan pembelian, kepuasan dan loyalitas, dan apakah strategi produk, harga, distribusi, dan promosi Bubuk Teh sangat berpengaruh bagi calon pembeli dalam menentukan pembelian, serta bagaimana pola hubungan kausalitas keseluruhan faktor-faktor tersebut dengan kinerja organisasi, masih perlu dikaji secara lebih ilmiah.

Berdasarkan latar belakang di atas, maka tujuan penelitian ini adalah: (1) mengetahui pengaruh produk terhadap keputusan konsumen, (2) mengetahui pengaruh harga terhadap keputusan konsumen, (3) mengetahui pengaruh distribusi terhadap keputusan konsumen, (4) mengetahui pengaruhpromosi terhadap keputusan konsumen, (5) mengetahui pengaruhproduk terhadap kepuasan konsumen, (6) mengetahui pengaruh harga terhadap kepuasan konsumen; (7) mengetahui pengaruh distribusi terhadap kepuasan konsumen, (8) mengetahui pengaruhpromosi terhadap kepuasan konsumen, (9) mengetahui pengaruh keputusan terhadap kepuasan konsumen, (10) mengetahui pengaruhkeputusan terhadap loyalitas konsumen, (11) mengetahui pengaruh kepuasan terhadap loyalitas konsumen. 


\section{LANDASAN TEORI}

\section{Definisi Bauran Pemasaran}

Menurut Kotler (2000:18), bauran pemasaran adalah seperangkat alat pemasaran yang digunakan perusahaan untuk terus-menerus mencapai tujuan pemasarannya di pasar sasaran. Menurut Swastha dan Irawan (2001:78), bauran pemasaran adalah kombinasi dari empat variabel atau kegiatan yang merupakan inti dari sistem pemasaran perusahaan, yakni: produk, struktur harga, kegiatan promosi, dan sistem distribusi.

\section{Komponen Bauran Pemasaran a. Produk}

Produk mempunyai arti yang sangat penting bagi sebuah perusahaan. Oleh sebab itu, disamping sebagai dasar menentukan kebijakan pemasaran juga merupakan gambaran perusahaan di mata masyarakat konsumen. Jika produk yang ditawarkan dapat memuaskan keinginan konsumen merupakan gambaran keberhasilan. Tentu saja produk di sini tidak hanya terbatas wujud fisik, tetapi juga kualitas model dan apa saja yang dapat memuaskan keinginan konsumen. Kotler dan Armstrong (2008:266), mendefinisikan produk sebagai segala sesuatu yang dapat ditawarkan kepada pasar agar menarik perhatian, akuisisi, pengggunaan, atau konsumsi yang dapat memuaskan suatu kegiatan atau kebutuhan.

\section{b. Harga}

Menurut Swasta dan Irawan (2001:241), harga adalah jumlah uang (ditambah beberapa produk kalau mungkin) yang dibutuhkan untuk mendapatkan sejumlah kombinasi dari produk dan pelayanannya. Menurut Effendi (2007:61-62), tujuan dari penetapan harga sangat diperlukan dalam kegiatan pemasaran. Hal ini karena tujuan penetapan harga 3 akan menjadi acuan bagi perusahan dalam menjalankan kegiatan pemasaran. Ada beberapa tujuan penetapan harga yang sering diambil, antara lain: 1. Memperoleh laba yang maksimum 2. Mendapatkan pangsa pasar tertentu 3. Memerah pasar 4. Mencapai tingkat hasil penerimaan penjualan maksimum pada waktu tertentu 5. Mencapai keuntungan yang ditargetkan 6. Mempromosikan produk

\section{Perilaku Konsumen}

Kotler \& Keller (2009:166) menyatakan bahwa perilaku konsumen adalah studi tentang bagaimana individu, kelompok, dan organisasi memilih, membeli, menggunakan, bagaimana barang, jasa, ide atau pengalaman untuk memuaskan kebutuhan dan keinginan mereka.

\section{METODOLOGI}

Kegiatan penelitian adalah menemukan variabel endogen berupa loyalitas konsumen yang diukur dari keputusan dan kepuasan, dan pengaruh variabel eksogen berupa bauran pemasaran, yaitu: produk, harga, promosi, dan distribusi. Penelitian ini termasuk dalam penelitian penjelasan (explanatory research) karena penelitian ini bermaksud menjelaskan hubungan kausal (sebab akibat) antar variabel melalui pengujian hipotesis yang telah dirumuskan (Hair, 1998:21).

Data dikumpulkan dengan pendekatan cross sectional, yaitu data dikumpulkan satu kali. Wawancara dilakukan secara personal oleh salesman Bubuk Teh yang selalu melakukan kunjungan rutin kepada konsumen. Teknik penentuan sampel yang dipilih untuk menjadi responden dalam penelitian ini menggunakan teknik accidental sampling yang berarti penelitian dilakukan secara langsung dengan mengabaikan status, nama, atau predikat responden (Ghozali, 2008:42). Jumlah sampel dalam penelitian ini ditetapkan sebanyak

260 (dua ratus enam puluh) responden. Populasi dalam penelitian ini terbatas pada konsumen yang membeli Bubuk Teh yang berhubungan dengan digunakannya model persamaan struktural (Structural Equation Modelingatau SEM) dengan AMOS, maka berdasarkan "rule of thumb" yaitu dengan mengkonversi diagram jalur ke persamaan, mengkorversi spesifikasi model tersebut ke dalam rangkaian persamaan yang dibangun yang terdiri dari:

a. Persamaan-persamaan struktural (structural equations). Persamaan ini dirumuskan untuk menyatakan kausalitas antar berbagai konstruk. 
b. Persamaan spesifikasi model pengukuran (measurement model), yaitu menentukan variabel mana yang mengukur konstruk yang mana, serta menentukan serangkaian matrik yang menunjukkan korelasi antar konstruk dan variabel yang dihipotesiskan (Ferdinand, 2002:30). Persamaan yang diajukan untuk model konseptual disajikan sebagai berikut:

1. $\mathrm{Y}_{1}=\gamma_{1.1} \mathrm{X}_{1}+\gamma_{1.2} \mathrm{X}_{2}+\gamma_{1.3} \mathrm{X}_{3}+\gamma_{1.4} \mathrm{X}_{4}+€_{1}$

2. $\mathrm{Y}_{2}=\gamma_{2} .1 \mathrm{X}_{1}+\gamma_{2} .2 \mathrm{X}_{2}+\gamma_{2} .3 \mathrm{X}_{3}+\gamma_{2} .4 \mathrm{X}_{4}+€_{2}$

3. $\mathrm{Y}_{2}=\gamma_{2.1} \mathrm{X}_{1}+\gamma_{2.2} \mathrm{X}_{2}+\gamma_{2.3} \mathrm{X}_{3}+\gamma_{2.4} \mathrm{X}_{4}+\beta_{2.1} \mathrm{Y}_{1}+€_{3}$

4. $\mathrm{Y}_{3}=\gamma_{3} .1 \mathrm{X}_{1}+\gamma_{3} .2 \mathrm{X}_{2}+\gamma_{3} .3 \mathrm{X}_{3}+\gamma_{3} .4 \mathrm{X}_{4}+\beta_{3} .1 \mathrm{Y}_{1}+€_{4}$

5. $Y_{3}=\gamma_{3} .1 X_{1}+\gamma_{3} .2 X_{2}+\gamma_{3} .3 X_{3}+\gamma_{3} .4 X_{4}+\beta_{3} .2 Y_{2}+€_{5}$

dimana:

$\gamma, \beta$ : (gamma, beta) koefisien path dari variabel

$\gamma \quad$ : Hubungan langsung variabel eksogen terhadap variabel endogen $\beta \quad$ : Hubungan langsung variabel endogen terhadap variabel eksogen $\mathrm{X}_{1} \quad$ : Produk

$\mathrm{X}_{2} \quad$ : Harga

$\mathrm{X} 3$ : Distribusi

$\mathrm{X}_{4}$ : Promosi

Y1 : Keputusan

$\mathrm{Y}_{2}$ : Kepuasan

Y3 : Loyalitas

$€ \quad$ (measurement error) tingkat kesalahan

\section{HASIL DAN PEMBAHASAN}

Pada tahap ini akan dibahas mengenai uji kesesuaian model dan uji signifkansi kausalitas. Hasil pengujian dengan program AMOS versi 5.0 memberikan hasil model SEM yang menunjukkan pengaruh bauran pemasaran (produk, harga, distribusi, dan promosi) terhadap keputusan dan kepuasan, serta keputusan dan kepuasan terhadap loyalitas konsumen Bubuk Teh di Sidamanik.Kesimpulan hasil pengujian hipotesis terdata dalam tabel berikut:

Tabel 1: Hasil Pengujian Hipotesis

\begin{tabular}{|c|c|c|c|c|c|}
\hline$\stackrel{\text { Variabel }}{\longrightarrow}$ & Estimate & $\begin{array}{r}\text { Standar } \\
\text { Error }\end{array}$ & $\begin{array}{c}\text { Critical } \\
\text { Ratio }\end{array}$ & $\begin{array}{c}\text { Profitabilitas } \\
\text { Error }\end{array}$ & $\begin{array}{c}\text { Kesimpulan } \\
\text { Hipotesis }\end{array}$ \\
\hline $\mathrm{X}_{1} \mathrm{Y}_{1}$ & 0,098 & 0,354 & 2,270 & 0,027 & $\mathrm{H}_{1}$ Diterima \\
\hline $\mathrm{X}_{2}$ & 0,085 & 0,965 & 0,073 & 0,942 & H3 Ditolak \\
\hline $\mathrm{X}_{3}$ & 0,099 & 1,656 & 2,782 & 0,006 & H5 Diterima \\
\hline $\mathrm{X}_{4}$ & 0,469 & 0,208 & 2,694 & 0,007 & $\mathrm{H} 7$ Diterima \\
\hline $\mathrm{X}_{1}$ & 0,381 & 0,369 & 3,032 & 0,000 & $\mathrm{H}_{2}$ Diterima \\
\hline $\mathrm{X}_{2}$ & 0,288 & 1,014 & 2,242 & 0,029 & $\mathrm{H}_{4}$ Diterima \\
\hline $\mathrm{X}_{3}$ & 0,513 & 1,726 & 0,422 & 0,673 & $\mathrm{H}_{6}$ Ditolak \\
\hline $\mathrm{X} 4$ & 0,154 & 0,212 & 0,896 & 0,370 & H8 Ditolak \\
\hline $\mathrm{Y}_{1} \vec{\longrightarrow} \mathrm{Y}_{2}$ & 0,431 & 0,131 & 3,393 & 0,000 & H9 Diterima \\
\hline
\end{tabular}




\begin{tabular}{|l|l|l|l|l|l|l|}
\hline $\mathrm{Y}_{1}$ & $\mathrm{Y}_{3}$ & 0,384 & 0,064 & 2,859 & 0,004 & H10 Diterima \\
\hline $\mathrm{Y}_{2}$ & $\mathrm{Y}_{3}$ & 0,246 & 0,053 & 2,130 & 0,033 & $\mathrm{H}_{11}$ Diterima \\
\hline
\end{tabular}

Sumber: Data diolah, 2012

Secara garis besar penelitian ini menunjukkan keseluruhan hipotesis yang diajukan dapat diterima. Dalam hal ini terdapat pengaruh yang signifikan dari produk, distribusi, dan promosi terhadap keputusan; terdapat pengaruh yang signifikan dari produk dan harga terhadap kepuasan; terdapat pengaruh yang signifikan dari keputusan terhadap kepuasan; dan terdapat pengaruh yang signifikan dari keputusan dan kepuasan terhadap loyalitas. Sedangkan hipotesis yang menyatakan bahwa harga berpengaruh terhadap keputusan, serta distribusi dan promosi berpengaruh terhadap kepuasan, tidak terbukti pengaruhnya.

\section{KESIMPULAN}

Kesimpulan yang dapat diambil dalam penelitian ini adalah sebagai berikut:

1. Produk berpengaruh positif dan signifikan terhadap keputusan konsumen.

2. Harga berpengaruh positif namun tidak signifikan terhadap keputusan konsumen.

3. Distribusi berpengaruh positif dan signifikan terhadap keputusan konsumen.

4. Promosi berpengaruh positif dan signifikan terhadap keputusan konsumen.

5. Produk berpengaruh positif dan signifikan terhadap kepuasan konsumen.

6. Harga berpengaruh positif dan signifikan terhadap kepuasan konsumen

7. Distribusi berpengaruh positif namun tidak signifikan terhadap kepuasan konsumen

8. Promosi berpengaruh positif namun tidak signifikan terhadap kepuasan konsumen.

9. Keputusan berpengaruh positif dan signifikan terhadap kepuasan konsumen.

10. Keputusan berpengaruh positif dan signifikan terhadap loyalitas konsumen.

11. Kepuasan berpengaruh positif dan signifikan terhadap loyalitas konsumen.

\section{DAFTAR REFERENSI}

BPS Kabupaten Sidamanik. 2012. Hasil Sensus Penduduk Tahun 2000. Ferdinand, Augusty. 2002. Structural Equation Modelling Dalam Penelitian Manajamen: Aplikasi Model-Model Rumit Dalam Penelitian Untuk Tesis Dan Disertasi Doktor, Edisi 2. Semarang: BPUNDIP.

Ghozali, Imam. 2008. Model Persamaan Struktural Konsep Dan Aplikasi Dengan Program AMOS Versi 16.0. Semarang: Badan Penerbit Universitas Diponegoro.

Hair, J.F., Et Al. 1998. Multivariats Data Analysis With Readings. New Jersey: Prentice Hall.

Kotler, Philip dan Kevin, Keller. 2009. Manajemen Pemasaran. Alih Bahasa: Imam Nuraman, Edisi Ketiga. Jakarta: Penerbit Erlangga.

Malcolm, Mcdonald. 1992. Strategi Pemasaran. Jakarta: PT. Elex Media Komputindo. Mowen, John C., dan Minor, Michael. 2002. Perilaku Konsumen, Edisi Kelima. Jakarta: Erlangga. 